sweating, have no effect on heat production and temperature elevation. They begin to act when the fever has reached its highest point (Goodman and Gilman, 1955). In laboratory studies of antipyretic agents, aspirin and acetaminophen failed, whereas barbiturates were effective in retarding temperature elevation induced by radiotherm diathermy in animals. High doses of salicylates that cause hyperventilation and respiratory alkalosis lowered the threshold convulsive temperature and exacerbated the hyperthermia-induced seizure. (Millichap JG et al. Neurology 1960;10:575). The prevention of febrile seizures by anticonvulsant medications may be as much antipyretic as anticonvulsant effect. Future research in the development of more effective antipyretics should target heat production more than heat dissipation. The authors from Finland comment on the inhibition of different prostaglandins by antipyretics and the potential for different effects on seizure recurrence.

\title{
FEBRILE SEIZURES AND COGNITIVE OUTCOME
}

The association between febrile seizures and cognitive function in young adulthood was examined in a population-based study of Danish conscripts at Aarhus University Hospital, Denmark. Men with a history of epilepsy were excluded. Analysis of health-care databases found that $2.8 \%$ of 18,276 eligible conscripts had a record of hospitalization for febrile seizures. Prevalence of IQ scores in the bottom quartile $(<37)$ was $25.3 \%$ and $27.6 \%$ for men with and without febrile seizures, respectively. Low IQ scores were slightly more prevalent in men born premature $(30 \%)$, small for gestational age $(32 \%)$, mother $<20$ years $(36 \%)$, or parity $>3(33 \%)$. Adjusted prevalence ratios for having a group IQ score in the bottom quartile was 1.09 for men with febrile seizures and 1.08 for those without.. The prevalence ratios according to age at febrile seizure onset were 1.38 for 3 months to $<1 \mathrm{yr}$; 0.98 for 1 to 2 years; and 1.14 for 3 to 5 years. Except for men whose febrile seizures occurred before age 1 year, there was little evidence of low cognitive function associated with a history of febrile seizures. (Noergaard M, Ehrenstein V, Mahon BE, Nielsen GL, Rothman KJ, Sorensen HT. Febrile seizures and cognitive function in young adult life: a prevalence study in Danish conscripts. J Pediatr Sept 2009;155:404-409). (Respond: Mette Noergaard MD PhD, Dept Clinical Epidemiology, Aarthus University Hospital, Sdr Skovve 15, DK-9000 Aalborg, Denmark. E-mail: m.noergaard@rn.dk).

COMMENT. Decreased cognitive function in young adults with a history of febrile seizures before age $1 \mathrm{yr}$ is previously unreported. In another Danish study, children with a febrile seizure early $(<1 \mathrm{yr})$ or late $(>3 \mathrm{yr})$ had a higher rate of epilepsy compared to children with onset between 1 and 3 years (Vestergaard $M$ et al. Am J Epidemiol 2007;165:911-918). Abnormal MRIs in 11.4\% of children with first simple febrile seizures, reported in a NY-Presbyterian Hospital study, was also an unexpected finding, given the presumed benign nature of the febrile seizure. (Hesdorffer DC et al. Epilepsia 2008;49:765771; Ped Neur Briefs June 2008;22:47-48). MRI is not usually recommended in children with simple febrile seizures, in accordance with AAP guidelines.

\section{BULGING FONTANELLE AND NEED FOR LUMBAR PUNCTURE}

Etiologies of bulging fontanelle and fever and clinical evidence for lumbar puncture were determined from medical records of 153 infants treated at Assaf Harofeh Medical 